\title{
\begin{tabular}{l|l|l} 
Jurnal Eksplorasi Akuntansi & ISSN : 2656-3649 (Online) \\
Vol. 2, No 4, Seri B, November 2020, Hal 3553-3557 & http://jea.ppj.unp.ac.id/index.php/jea/issue/view/30
\end{tabular}
}

\section{PKM Literasi Keuangan Melalui Pelatihan Trading Saham Syariah Pada Guru-Guru MGMP Akuntansi dan Ekonomi SMA Se-Kota Pariaman}

\author{
Erly Mulyani', Halkadri Fitra ${ }^{2}$, Salma Taqwa ${ }^{3}$, Henri Agustin ${ }^{4}$, Fefri Indra Arza ${ }^{5}$ \\ 1,2,3,4,5 Jurusan Akuntansi Fakultas Ekonomi Universitas Negeri Padang \\ *Korespondensi: erly1978@gmail.com
}

Abstract: This community service aims to increase partner literacy about Islamic stock trading. Partners in this service are MGMP accounting and economics teachers in SMA Pariaman City. This community service provides training, discussion, practice and monitoring to partners. There were 25 participants who took part in this activity. After the training, the participants were able to make transactions in the capital market. This can be seen from the activities of the participants who directly buy and sell Islamic shares using the POST PRO application.

Keywords: Literacy, Trading, Sharia Shares

How to cite (APA 6 $^{\text {th }}$ style):

Mulyani, E; Fitra, H; Taqwa, S; Agustin, H; Arza, F.I. (2020). PKM Literasi Keuangan Melalui Pelatihan Trading Saham Syariah Pada Guru-Guru MGMP Akuntansi dan Ekonomi se-Kota Pariaman. Jurnal Eksplorasi Akuntansi, 2(4), Seri B, 3553-3557.

\section{PENDAHULUAN}

Literasi keuangan merupakan suatu rangkaian proses atau kegiatan untuk meningkat pengetahuan (knowledge), keterampilan (skill) dan keyakinan (confidendence) konsumen maupun masyarakat agar mereka mampu mengelola keuangan pribadi dengan lebih baik. Menurut Kepala Subbagian Hubungan Kelembagaan Pasar Modal Syariah Otoritas Jasa Keuangan (OJK) Andry Wicaksono mengatakan indeks literasi masyarakat atas pasar modal syariah masih rendah. Survei yang dilakukan oleh OJK menunjukkan kecilnya angka pengetahuan masyarakat tentang pasar modal syariah. Dari survei itu, masyarakat yang mengenal pasar modal syariah hanya sekitar 0,02 persen. Dari angka tersebut, hanya 0,01 persen yang menjadi investor (Tempo.co. 10 Maret 2018 .Bisnis .tempo. com), padahal Indonesia adalah negara populasi muslim terbesar didunia. Pasar modal syariah menjadi potensi yang cukup penting di Indonesia

Pasar modal menurut Undang-undang Nomor 8 Tahun 1995 tentang Pasar Modal adalah kegiatan yang bersangkutan dengan penawaran umum dan perdagangan efek, perusahaan publik yang berkaitan dengan efek yang diterbitkannya, serta lembaga dan profesi yang berkaitan dengan efek. Berdasarkan definisi tersebut, terminologi pasar modal syariah dapat diartikan sebagai kegiatan dalam pasar modal sebagaimana yang diatur dalam UU yang tidak bertentangan dengan prinsip syariah. Oleh karena itu, pasar modal syariah bukanlah suatu sistem yang terpisah 
dari sistem pasar modal secara keseluruhan. Secara umum kegiatan Pasar Modal Syariah tidak memiliki perbedaan dengan pasar modal konvensional, namun terdapat beberapa karakteristik khusus Pasar Modal Syariah yaitu bahwa produk dan mekanisme transaksi tidak bertentangan dengan prinsip-prinsip syariah.

Edukasi dan penelitian tentang pasar modal telah banyak dilakukan baik oleh kalangan akademisi maupun para praktisi, tetapi edukasi dan penelitian itu lebih banyak pada fokusnya pada pasar modal pada umumnya, seperti yang dilakukan oleh Setiawan (2018), sedangkan untuk pasar modal syariah masih jarang dilakukan. Dengan kemajuan teknologi sekarang ini maka investasi di pasar modal sudah di permudah dengan internet. Shariah Online Trading System (SOTS) adalah sistem transaksi saham syariah secara online yang memenuhi prinsip-prinsip syariah di pasar modal. SOTS dikembangkan oleh anggota bursa sebagai fasilitas atau alat bantu bagi investor yang ingin melakukan transaksi saham secara syariah. SOTS disertifikasi oleh DSN-MUI karena merupakan penjabaran dari fatwa DSN-MUI No. 80 tahun 2011 tentang Penerapan Prinsip Syariah Dalam Mekanisme Perdagangan Efek Bersifat Ekuitas Di Pasar Reguler Bursa Efek (idx.co.id)

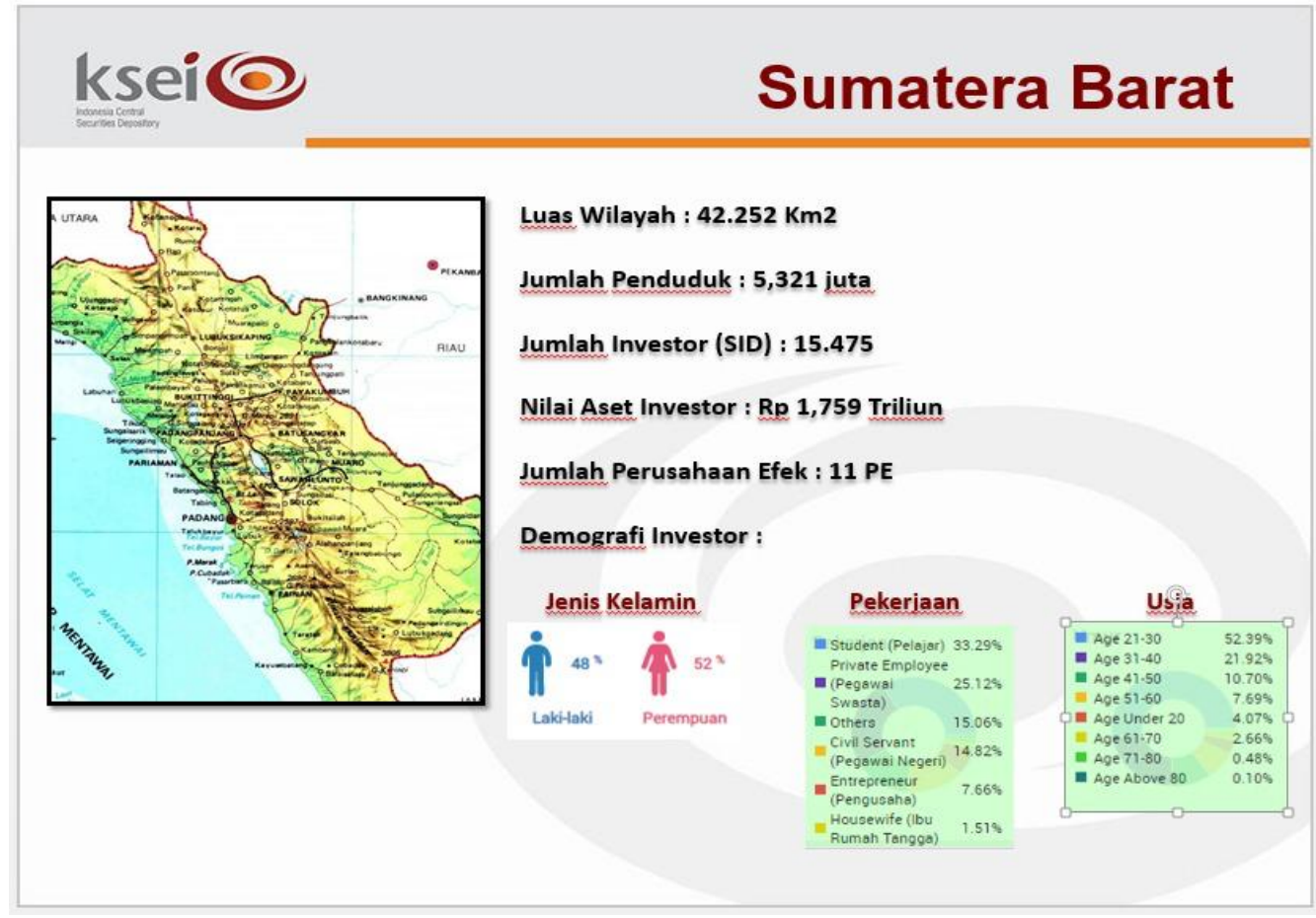

Gambar 1. Rekapitulasi investor di Sumatera Barat

Dilihat dari data pada gambar 1 terlihat bahwa Jumlah investor di Sumatera Barat masih sedikit yaitu 15.475 dengan jumlah penduduk 5,321 juta. Hal ini disebabkan oleh masih kurangnya literasi kepada masyarakat luas seperti yang disampaikan oleh Irwan Abdallah yang merupakan kepala divisi pasar Modal Syariah Bursa Efek Indonesia (BEI) (republika.co.id, Selasa 19 Mar 2019 05:05 WIB). Sedangkan jumlah masyarakat yang memiliki rekening efek di kota Pariaman baru berjumlah 311 dan yang aktifnya hanya 275, hal ini memperlihatkan bahwa masih sangat sedikit masyarakat yang mengenal pasar modal. 
Guru yang merupakan elemen yang sangat penting dalam kemajuan pendidikan generasi penerus bangsa, untuk mencetak generasi yang cerdas dalam berinvestasi, maka guru-gurunya harus lebih dahulu paham tentang pasar modal dan bisa langsung melakukan transaksi di pasar modal. Investasi sangat penting bagi kebutuhan masa depan setiap orang. Berbagai instrumen investasi tersedia dipasar saat ini, dan diharapkan guru dapat memanfaatkan produk-produk tersebut. Namun Maraknya penipuan dengan berkedok investasi membuat kita harus jeli memilih produk-produk investasi yang ada dipasaran agar tidak tertipu. Demikian juga dengan investasi saham dipasar modal, meskipun memberikan peluang return yang tinggi dibanding produk lainnya, namun seorang investor dituntut jeli dalam melakukan transaksi.

Berdasarkan hasil kunjungan dan diskusi tim pengusul dengan para guru ekonomi di SMA 1 Pariaman terdapat masalah yang mereka hadapi yaitu : masih adanya keraguan apakah investasi di pasar modal tersebut halal atau haram, masih adanya anggapan bahwa investasi pasar modal itu hanya untuk orang yang memiliki banyak dana dan mereka tidak mengetahui cara membuka rekening efek. Berdasarkan hasil diskusi dengan mitra maka tim pengabdi tertarik mengadakan pengabdian di Kota Pariaman dengan pesertanya adalah guru-guru mata pelajaran ekonomi se kota Pariaman

\section{METODE PELAKSANAAN}

Metode yang digunakan dalam kegiatan pengabdian kepada masyarakat ini adalah memberikan pelatihan, diskusi, praktik dan monitoring kepada khalayak sasaran sehingga mereka mengalami proses mendengar, mengetahui, mencoba, mengevaluasi, menerima, meyakini, dan melaksanakan peningkatan pengetahuan dan keterampilan baru yang mereka miliki dengan langkah-langkah berikut:

1. Metode pelatihan dan diskusi

Metode ini di pilih untuk menyampaikan dan mengenalkan mitra mengenai apa itu saham syariah, sehingga mitra dapat membuat keputusan pada saat melakukan investasi pada pasar modal

2. Metode praktek dan monitoring

Setelah diperkenalkan kepada mitra mengenai apa itu saham syariah dan bagaimana cara mengambil keputusan dalam investasi pasar modal, selanjutnya mitra di bukakan rekening efek melalui Galeri Investasi Bursa Efek Indonesia (GIBEI) Fakultas Ekonomi UNP dimana proses pembukaan selama kurang lebih 2 minggu. Setelah rekening selesai maka dilakukan praktek secara langsung membeli salah satu saham syariah yang listing di bursa menggunakan aplikasi POSPRO dari Panin sekuritas.

\section{HASIL DAN PEMBAHASAN}

Peserta dari kegiatan pengabdian ini adalah para guru majelis guru mata pelajaran (MGMP) akuntansi dan ekonomi di Kota Pariaman. Peserta dari kegiatan ini berjumlah 25 orang. Pelaksanaan pengabdian ini dilaksanakan pada bulan September dan Oktober 2020. Peserta datang melalui undangan secara resmi melalui ketua MGMP.

Pelatihan ini dilaksanakan di SMA 1 Pariaman. Para materi dan instruktur yang terlibat dalam kegiatan ini memberikan pengetahuan dan praktikum cara mengambil keputusan berinvestasi di pasar modal syariah dengan memberikan edukasi tentang pasar modal syariah dan menjelaskan perbedaan antara saham syariah dengan saham non syariah, sehingga para guru dapat mengambil keputusan yang tepat dalam berinvestasi di pasar modal. Disamping ini selain menambah wawasan para pemateri langsung mengajarkan kepada guru-guru pratek secara langsung bagaimana cara membeli dan menjual saham syariah secara online. 


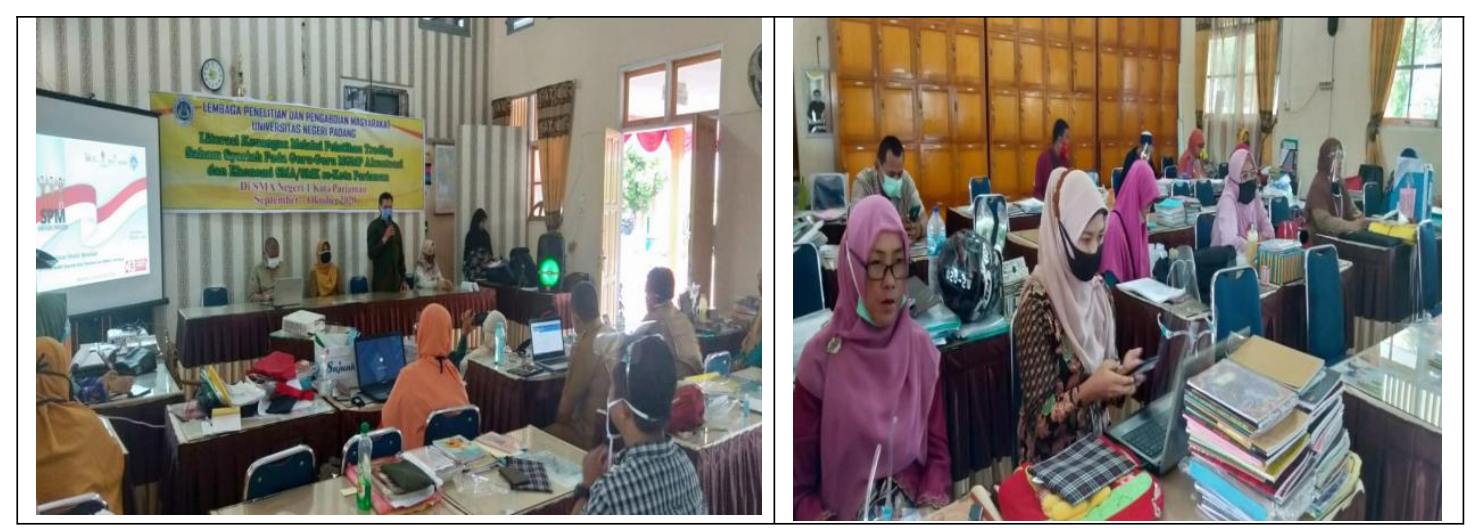

Gambar 2. Kegiatan Pelatihan dan Demonstrasi Saham Syariah

Pemateri yang memberikan pelatihan adalah orang-orang yang kompeten pada bidangnya, seperti Kapala Kantor Bursa Efek Indonesia wilayah Sumatera Barat, Dosen-dosen Fakultas Ekonomi Universitas Negeri Padang. Pemateri dari dosen memberikan materi tentang pengenalan pasar modal, sedangkan untuk literasi saham syariah diberikan oleh kepala kantor BEI wilayah Sumatera Barat. Untuk pembukaan rekening efek para mitra dilakukan melalui Galeri Investasi Bursa Efek Indonesia Universitas Negeri Padang, jadi para guru-guru pada pelatihan ini diminta untuk membuka rekening efek, sehingga mereka dapat langsung mempraktekkan bagaimana cara membeli saham syariah. Dalam kegiatan ini tim pelaksana melakukan evaluasi terhadap pengetahuan peserta dengan menggunakan konsep diskusi, sehingga peserta bisa mengungkapkan apa saja yang mereka belum pahami. Dengan diadakannya diskusi maka diharapkan dapat terlihat pemahaman dan pengetahui peserta tentang materi yang diberikan.

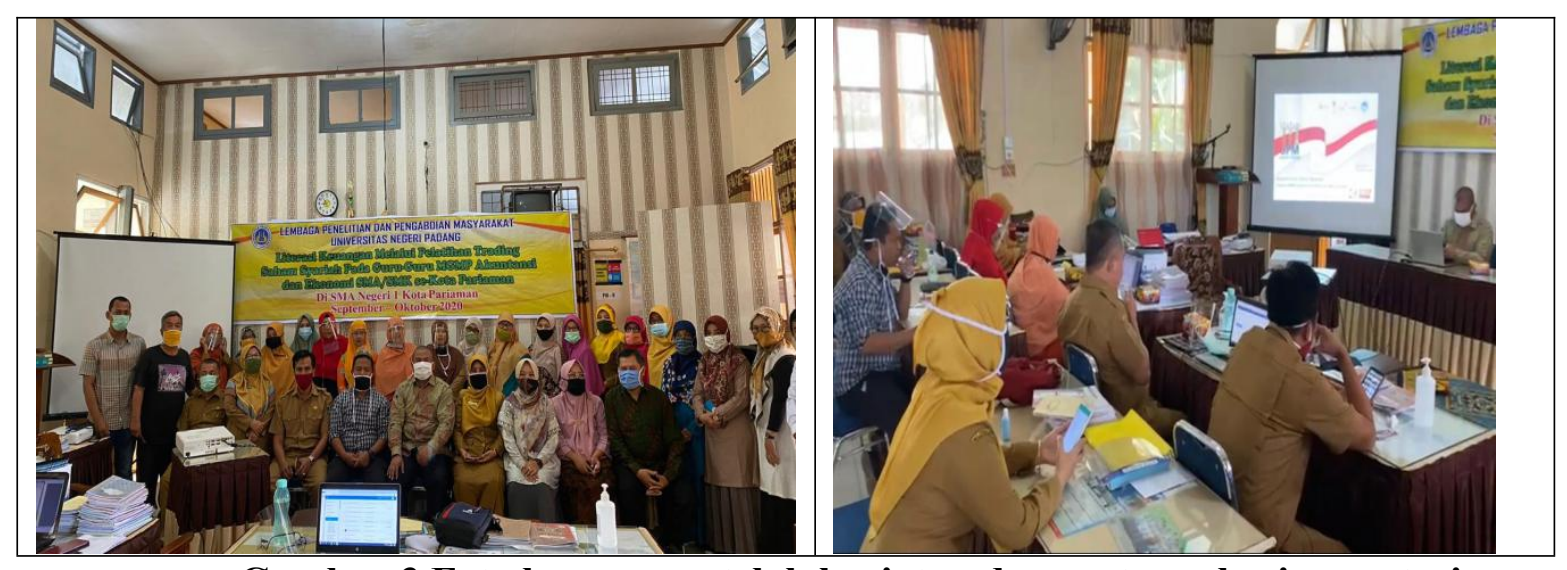

Gambar 3.Foto bersama setelah kegiatan dan saat pemberian materi

\section{KESIMPULAN}

Dari kegiatan pengabdian yang berjudul Literasi Keuangan Melalui Pelatihan Trading Saham Syariah Pada Guru-Guru MGMP Akuntansi dan Ekonomi SMA/SMK se-Kota Pariaman, dapat di ketahui bahwa sebelum pelatihan masih banyak peserta tidak tahu tentang investasi di pasar modal syariah dan ada juga dari peserta belum tau tentang bagaimana cara membeli dan menjual saham. Setelah diadakan kegiatan pengabdian ini para guru mampu melakukan transaksi di pasar 
modal syariah dan mengambil keputusan investasi di pasar modal sehingga bisa mentransfer pengetahuanya kepada siswa-siswanya. Harapan lainnya yaitu para peserta tetap melakukan investasi untuk seterusnya dan menjadikan pasar modal sebagai media investasi.

\section{SARAN}

Saran-saran yang dapat diberikan untuk kegiatan-kegiatan pengabdian yang akan datang adalah:

1. Untuk kegiatan pengabdian kedepannya, disarankan agar kegiatan diawali dengan pelatihan pemahaman tentang investasi secara umum sehingga lebih mudah memahami investasi dan setelah pelatihan di lanjutkan dengan memberikan pengetahuan tentang resiko, return dan faktor faktor yang mempengaruhi pada investasi di pasar modal, agar para guru juga mengetahui resiko dan tingkat pengembalian jika melakukan investasi di pasar modal

2. Pengabdian-pengabdian yang dilakukan, memang sebaiknya dalam memilih khalayak sasaran bekerjasama dengan instansi/kelompok/organisasi yang terkait dengan khalayak sasaran sehingga keberlanjutan dari kegiatan pengabdian dapat terus dilanjutkan oleh organisasi bagi anggota yang lainnya yang tidak ikut dalam kegiatan, serta organisasi dapat memantau perkembangan dari anggota yang telah ikut pelatihan.

\section{UCAPAN TERIMA KASIH}

Tim Pengabdi mengucapkan terima kasih kepada Rektor, Lembaga Penelitian dan Pengabdian Kepada Masyarakat, Dekan Fakultas Ekonomi Universitas Negeri Padang, Kepala Sekolah SMA Negeri 1 Kota Pariman, Pemateri, dan MGMP Ekonomi dan Akuntansi Kota Pariaman yang telah memberi dukungan secara moril dan finansial terhadap pelaksanaan kegiatan pengabdian ini.

\section{DAFTAR PUSTAKA}

Abdalloh, Irwan. (2018) Pasar Modal Syariah. Penerbit: PT Elex Media Komputindo. Jakarta Jogiyanto. (2010). Teori Portofolio dan Analisis Investasi. Edisi 7. Yogyakarta: BPFEYogyakarta

Setiawan, Budi.(2018) Edukasi Literasi Keuangan Pasar Modal Pengurus PKK Kecamatan Sako Palembang. Jurnal Abdimas Mandiri Volume 2 No. 1 Juni

www.ojk.go.id

www.syariahsaham.com

www.idx.co.id 